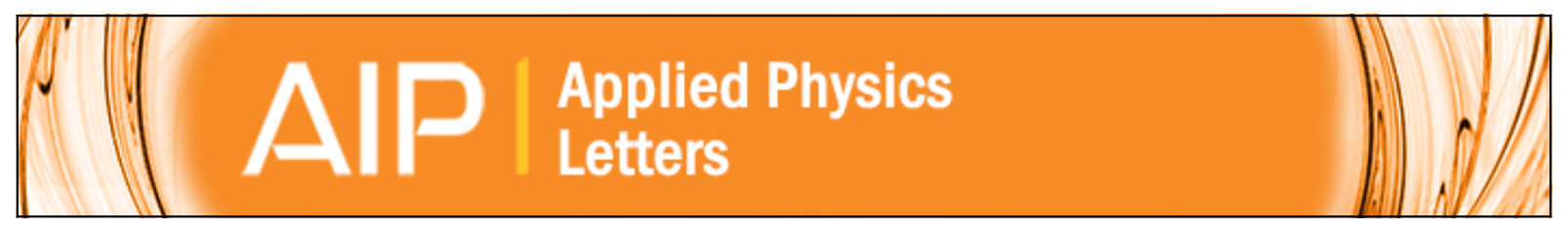

\title{
Metalorganic chemical vapor deposition of ferroelectric SrBi2Ta2O9 thin films
}

Tingkai Li, Yongfei Zhu, Seshu B. Desu, ChienHsiung Peng, and Masaya Nagata

Citation: Applied Physics Letters 68, 616 (1996); doi: 10.1063/1.116486

View online: http://dx.doi.org/10.1063/1.116486

View Table of Contents: http://scitation.aip.org/content/aip/journal/apl/68/5?ver=pdfcov

Published by the AIP Publishing

\section{Articles you may be interested in}

Impact of forming gas annealing on the dielectric properties of $\mathrm{SrBi} 2 \mathrm{Ta} 2 \mathrm{O} 9$ thin films prepared by metalorganic decomposition

J. Appl. Phys. 112, 084104 (2012); 10.1063/1.4761991

Structural and ferroelectric properties of the caxis oriented SrBi2Ta2O9 thin films deposited by the radio frequency magnetron sputtering

Appl. Phys. Lett. 69, 3839 (1996); 10.1063/1.117122

Oriented growth of SrBi2Ta2O9 ferroelectric thin films

Appl. Phys. Lett. 69, 1719 (1996); 10.1063/1.118008

Electrical properties of $\mathrm{SrBi2Ta2O9}$ thin films and their temperature dependence for ferroelectric nonvolatile memory applications

Appl. Phys. Lett. 68, 2300 (1996); 10.1063/1.116170

Preparation and ferroelectric properties of $\mathrm{SrBi} 2 \mathrm{Ta} 2 \mathrm{O} 9$ thin films

Appl. Phys. Lett. 66, 221 (1995); 10.1063/1.113140

\section{AlP Re-register for Table of Content Alerts}

\section{Create a profile.

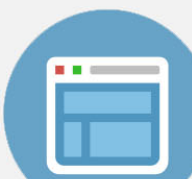 \\ Sign up today!}

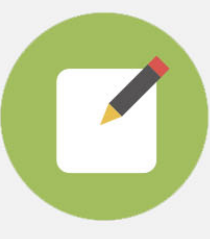




\title{
Metalorganic chemical vapor deposition of ferroelectric $\mathrm{SrBi}_{2} \mathrm{Ta}_{2} \mathrm{O}_{9}$ thin films
}

\author{
Tingkai Li, Yongfei Zhu, and Seshu B. Desu \\ Department of Materials Science and Engineering, Virginia Polytechnic Institute and State University, \\ Blacksburg, Virginia 24061
}

Chien-Hsiung Peng ${ }^{\text {a) }}$

CERAM Inc., Colorado Springs, Colorado 80906

Masaya Nagata

Functional Devices Laboratories, Sharp Corporation, Chiba 277, Japan

(Received 1 May 1995; accepted for publication 13 November 1995)

\begin{abstract}
Ferroelectric layered-oxides $\mathrm{SrBi}_{2} \mathrm{Ta}_{2} \mathrm{O}_{9}$ thin films were prepared on Pt coated $\mathrm{Si}$ wafers and single-crystal sapphire by metalorganic chemical vapor deposition (MOCVD). The films were specular and crack-free and showed complete crystallization at temperatures between 650 and $700{ }^{\circ} \mathrm{C}$. Good ferroelectric properties were obtained for a $200 \mathrm{~nm}$ thick film with Pt electrodes: $2 P_{r}$ and $E_{c}$ were about $8.3 \mu \mathrm{C} / \mathrm{cm}^{2}$ and $60 \mathrm{kV} / \mathrm{cm}$, respectively. The leakage currents were as low as $8 \times 10^{-9} \mathrm{~A} / \mathrm{cm}^{2}$ at $150 \mathrm{kV} / \mathrm{cm}$. The films also showed fatigue-free characteristics: no fatigue was observed up to $1.4 \times 10^{10}$ switching cycles. These high quality MOCVD films make high-intensity (>1 Mbit) nonvolatile memory devices possible. (C) 1996 American Institute of Physics. [S0003-6951(96)00505-7]
\end{abstract}

In recent years, ferroelectric thin films have been integrated into silicon integrated circuits to provide high speed, high $\mathrm{read} / \mathrm{write}$ endurance, high radiation hard, and low power consumption nonvolatile memory. ${ }^{1}$ However, the densities of current commercially available ferroelectric random access memory (FRAM) devices are still low. ${ }^{1}$ Although ferroelectric thin films have great potential for high-density (>Mbit) FRAMs, commercial usage has been hindered largely by serious degradation problems such as fatigue, imprint, retention, and aging that reduce the devices's lifetime. ${ }^{2}$ Since polarization must be reversed to read or write data in a memory cell, fatigue is a critical obstacle for practical use.

The most popular ferroelectric materials under investigations for nonvolatile memory applications are $\mathrm{PbZr}_{x} \mathrm{Ti}_{1-x} \mathrm{O}_{3}$ (PZT) because they have a high Curie temperature, large remanent polarization, and well-known properties. However, these ferroelectric capacitors have serious fatigue degradation problems after about $10^{8} \mathrm{read} / \mathrm{write}$ cycles that are not enough for intensive read/write applications. Several models can be found in the literature to explain the individual degradation mechanisms. Recently, Desu and Yoo $^{3}$ have proposed a unified model in which oxygen vacancies are cited as the common source for most degradation phenomena. The model suggests two possible solutions to overcome fatigue: reducing entrapments by changing the nature of the electrode/ferroelectric interface and controlling defect density of the ferroelectrics. Paz de Araujo, etc. ${ }^{4}$ indicated that fatigue also came from another different microscopic cause: stress relaxation of $90^{\circ}$ domains in pseudocubic crystals (such as lead zirconate titanate family). The $90^{\circ}$

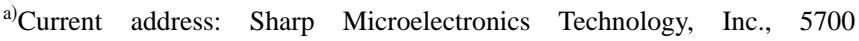
NW Pacific Rim Blvd., Camas, WA 98607. Electronic mail: cpeng@smtmhs.sharpwa.com
}

domain is more likely to be pinned than the $180^{\circ}$ domain. For this reason, reducing the $90^{\circ}$ domain may improve fatigue properties. Research has been conducted to improve the fatigue properties of PZT capacitors by using conductive oxide electrodes such as $\mathrm{La}_{x} \mathrm{Sr}_{1-x} \mathrm{CoO}_{3}$ and $\mathrm{RuO}_{2}$ or by doping $\mathrm{La}$ or $\mathrm{Nb}$ into the films. ${ }^{5-8}$ However, its disadvantage is that the resulting device is electrically "leaky," with dc leakage currents that may be too high for some nonvolatile memory device and for dynamic random access memories (DRAMSs). ${ }^{9}{ }^{10}$ An alternative approach is to find new ferroelectric materials with low intrinsic defect density such as $\mathrm{SrBi}_{2} \mathrm{Ta}_{2} \mathrm{O}_{9}$ (SBT) which are known as layered oxides.

Recently, SBT films were successfully prepared by several research groups ${ }^{11-17}$ using metalorganic decomposition $(\mathrm{MOD})^{11-15}$ or pulsed laser deposition (PLD) ${ }^{16,17}$ techniques. All the reported data on these materials showed very attractive ferroelectric properties and fatigue-free characteristics. However, neither MOD nor PLD are suitable for high density device applications due to their poor step coverage. In this letter, we present the structural, optical, and ferroelectric properties of MOCVD SBT films.

The SBN films were prepared on $\mathrm{Pt} / \mathrm{Ti} / \mathrm{SiO}_{2} / \mathrm{Si}$ substrates and sapphire disks by metalorganic chemical vapor deposition. The typical process conditions are shown in Table I. The bis(2,2,6,6-tetramethyl-3,5-heptanedionato) strontium hydrate $\left[\mathrm{Sr}(\mathrm{TMHD})_{2}\right]$, triphenylbismuth

TABLE I. Typical growth conditions of MOCVD $\mathrm{SrBi}_{2} \mathrm{Ta}_{2} \mathrm{O}_{9}$ films.

\begin{tabular}{ll}
\hline \hline Deposition pressure & $4-10$ Torr \\
Substrate temperature & $500-650{ }^{\circ} \mathrm{C}$ \\
$\mathrm{N}_{2}$ flow rate & $500 \mathrm{sccm}$ \\
$\mathrm{O}_{2}$ flow rate & $800 \mathrm{sccm}$ \\
Liquid source flow rate & $0.1-0.5 \mathrm{ml} / \mathrm{min}$ \\
Deposition time & $60-90 \mathrm{~min}$ \\
\hline \hline
\end{tabular}




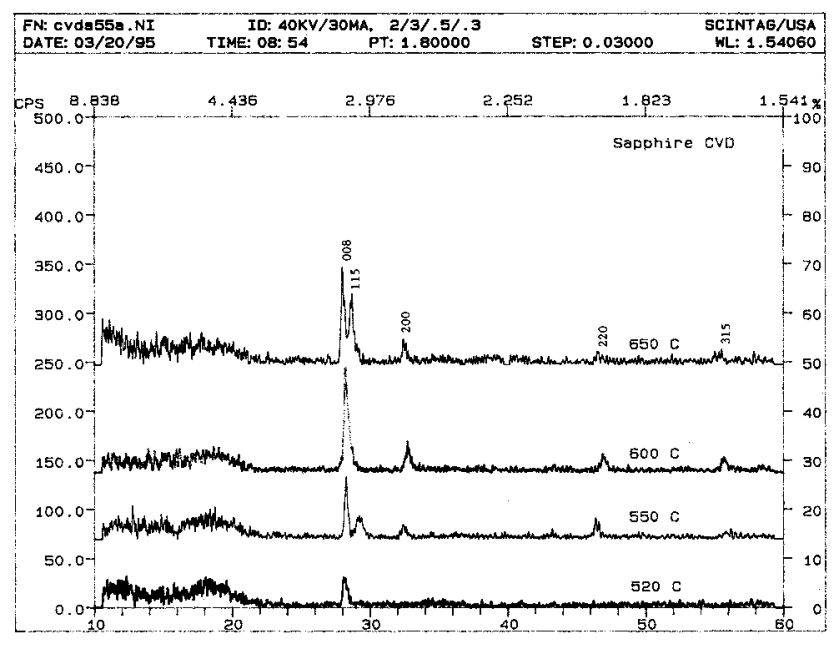

FIG. 1. XRD patterns of as-deposited MOCVD $\mathrm{SrBi}_{2} \mathrm{Ta}_{2} \mathrm{O}_{9}$ films on sapphire at various deposition temperatures.

$\left[\mathrm{Bi}\left(\mathrm{C}_{6} \mathrm{H}_{5}\right)_{3}\right]$, tantalum ethoxide $\left[\mathrm{Ta}\left(\mathrm{OC}_{2} \mathrm{H}_{5}\right)_{5}\right]$ were used as starting materials with a mixture of tetrahydrofuran, isopropanol, and tetraglyme in the molar ratio of $8: 2: 1$ as the solvent. The organic precursors were mixed, and dissolved in solvent to form source solution with concentration of $0.1-$ $0.5 \mathrm{M} / \mathrm{L}$ of SBT. The source solution was injected into the heated vaporization chamber to form precursor gases by a liquid pump. Smooth and specular SBT films were obtained. The thickness of SBN films were about $200 \mathrm{~nm}$. The phases of the film were identified using x-ray diffraction (XRD). The surface morphologies of the films were characterized by scanning electron microscopy (SEM). The optical properties of SBT films on $\mathrm{Pt} / \mathrm{Ti} / \mathrm{SiO}_{2} / \mathrm{Si}$ substrates were measured by both UV-Vis-NIR spectrophotometry and variable angle spectroscopic ellipsometry. The ferroelectric properties were measured using a standardized RT66A tester. The top electrodes used were sputtered platinum using a shadow mask. The area of the top electrode was $2.1 \times 10^{-4} \mathrm{~cm}^{2}$.

The films were deposited at temperatures ranging from 500 to $650^{\circ} \mathrm{C}$. As-deposited films were specular, crack-free, uniform, and adhered well on the substrates used and were highly transparent on sapphire substrates. These films also showed very smooth surfaces as viewed by means of both optical microscopy and scanning electron microscopy. The film growth rates were typically in the range of $3-5 \mathrm{~nm} / \mathrm{min}$.

Figure 1 shows the x-ray diffraction (XRD) patterns of the as-deposited SBT films on sapphire substrates as a function of deposition temperature. Only small x-ray peaks were observed when the films were deposited at $550{ }^{\circ} \mathrm{C}$ or lower. The major XRD peaks corresponding to (115) and (200) planes were observed when the films were deposited at $600{ }^{\circ} \mathrm{C}$. At a deposition temperature of $650{ }^{\circ} \mathrm{C}$, the films showed well-crystalline feature as can be seen in the figure. Figure 2 shows the XRD patterns of the $600{ }^{\circ} \mathrm{C}$ deposited MOCVD SBT films on sapphire as a function of postdeposition annealing temperature. As expected, at an annealing temperature of $700{ }^{\circ} \mathrm{C}$, sharp and numerous XRD peaks were observed, which indicated very well-crystallized films. For the surface morphology, the films appeared uniformly dis-

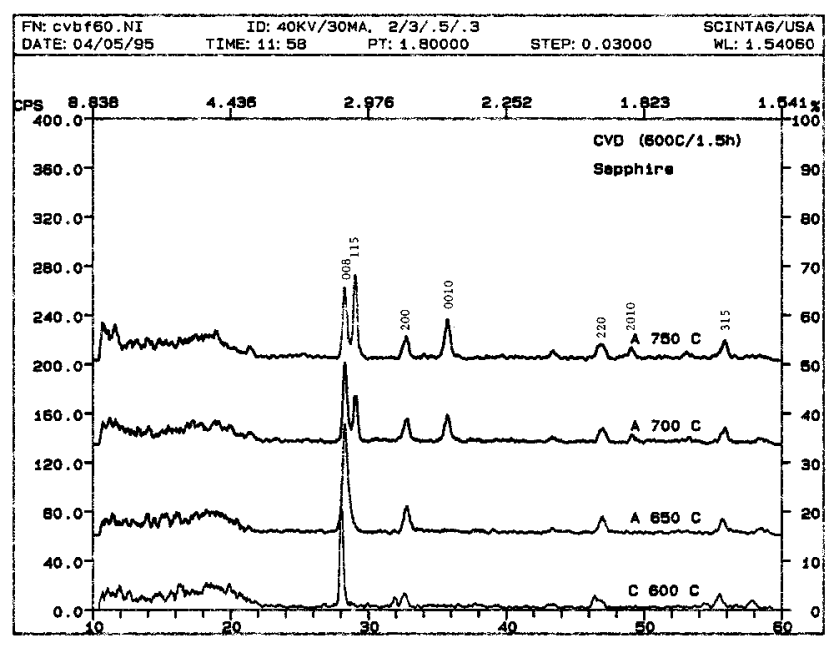

FIG. 2. XRD patterns of MOCVD $\mathrm{SrBi}_{2} \mathrm{Ta}_{2} \mathrm{O}_{9}$ films on sapphire. The films were deposited at $600{ }^{\circ} \mathrm{C}$ and annealed at various temperatures.

tributed fine grains and crack-free under SEM examinations. The SEM micrograph of the surface of annealed film is shown in Fig. 3. The average grain size is around $100 \mathrm{~nm}$. The refractive index of the films was around 2.3 measured by variable angle spectroscopic ellipsometry. This value is very close to that of $98 \%$ dense polycrystalline bulk SBT samples, ${ }^{18}$ which indicates a highly dense film.

The hysteresis loops of the MOCVD SBT films annealed at $750{ }^{\circ} \mathrm{C}$ are shown in Fig. 4. The thickness of the film was around $200 \mathrm{~nm}$. As can be seen in the figure, the loops were saturated at $3 \mathrm{~V}$. The remanent polarization $\left(2 P_{r}\right)$ and the coercive field $\left(E_{c}\right)$ of SBT films were $8.3 \mu \mathrm{C} / \mathrm{cm}^{2}$ and 60 $\mathrm{kV} / \mathrm{cm}$ at an applied voltage of $5 \mathrm{~V}$, respectively. Figure 5 shows fatigue characteristics of the film. The film was pulsed at $5 \mathrm{~V}$ of $1 \mathrm{MHz}$ bipolar square wave. The film did not show any fatigue after the sample was switched up to $1.4 \times 10^{10}$ cycles. Furthermore, no noticeable change on the hysteresis loops before and after the fatigue test was observed. It is believed that the superior fatigue properties of the SBT films are due to the Bi-layered structure. Unlike PZT, the thermal stability of the SBT compound is up to $11500^{\circ} \mathrm{C} .{ }^{19}$ Because the process temperature of $\mathrm{SBT}$ is below $800{ }^{\circ} \mathrm{C}$, there are no

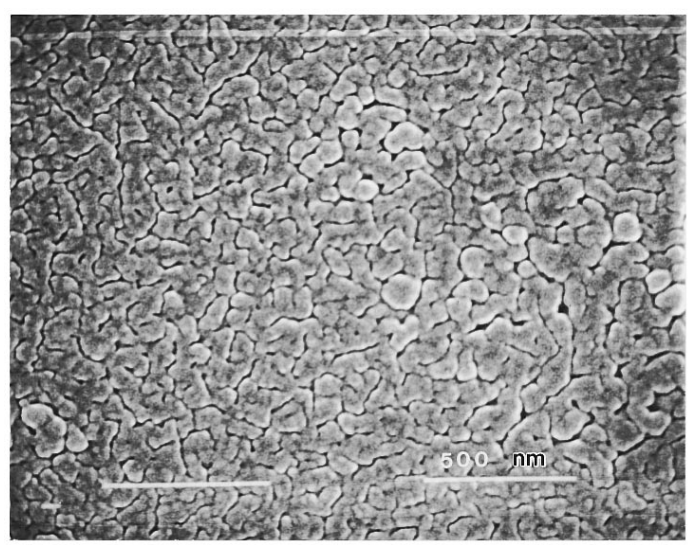

FIG. 3. SEM surface morphology of MOCVD $\mathrm{SrBi}_{2} \mathrm{Ta}_{2} \mathrm{O}_{9}$ films on Ptcoated Si substrates. 


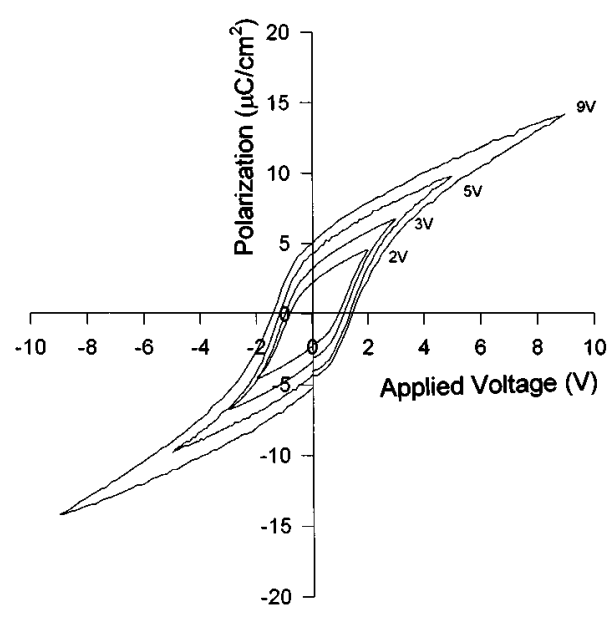

FIG. 4. Hysteresis loops of MOCVD $\mathrm{SrBi}_{2} \mathrm{Ta}_{2} \mathrm{O}_{9}$ films on Pt-coated $\mathrm{Si}$ substrates. The film thickness is around $200 \mathrm{~nm}$.

volatile species that result in defects at process temperature. On the other hand, Bi-layer oxides have large polarization along the $a$ or $b$ axis, but little or no polarization along the $c$ axis, thus most of the domain configuration in Bi-layer oxides is the $180^{\circ}$ domain. $^{8}$ For this reason, the BST has excellent fatigue properties.

Low leakage current density is another important consideration for memory device applications. Figure 6 shows the $I-V$ curve of a $200 \mathrm{~nm}$ thick MOCVD SBT films annealed at $750{ }^{\circ} \mathrm{C}$. Excellent $I-V$ characteristics were observed. The leakage current density at $150 \mathrm{kV} / \mathrm{cm}$ was around 8.4 $\times 10^{-9} \mathrm{~A} / \mathrm{cm}^{2}$. There is a significant difference in the measured room-temperature leakage current density values of the MOCVD films and the reported values for the laser ablated films. ${ }^{16}$ Under the same conditions of the applied electric field, the MOCVD derived films display leakage current densities at least an order of magnitude lower than the corresponding laser ablated films. Although further investigation is needed to identify the cause of this difference, one possible factor could be the smaller grain size and higher density of MOCVD films.

In summary, ferroelectric $\mathrm{SrBi}_{2} \mathrm{Ta}_{2} \mathrm{O}_{9}$ thin films were reproducibly fabricated on $\mathrm{Pt} / \mathrm{Ti} / \mathrm{SiO}_{2} / \mathrm{Si}$ and sapphire sub-

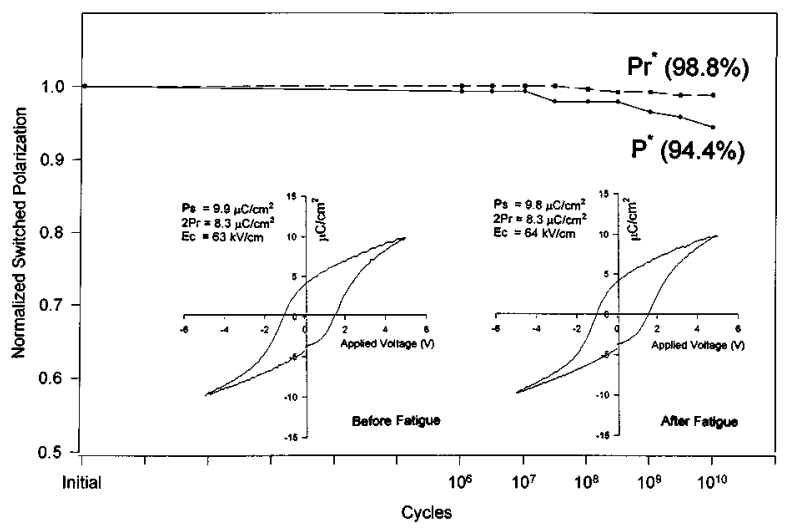

FIG. 5. Fatigue curves of MOCVD $\mathrm{SrBi}_{2} \mathrm{Ta}_{2} \mathrm{O}_{9}$ films on Pt-coated Si substrates. The hysteresis loops before and after fatigue test are also shown.

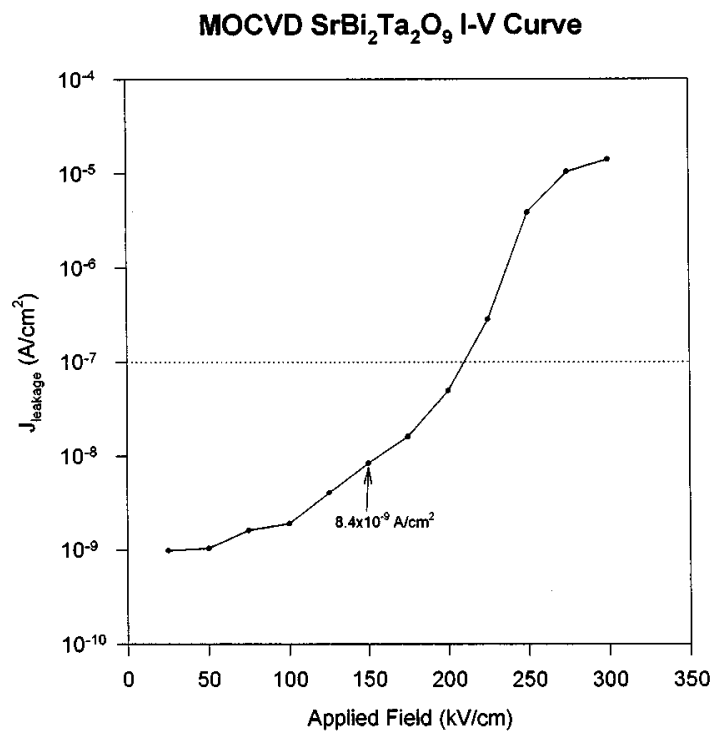

FIG. 6. Leakage current of MOCVD $\mathrm{SrBi}_{2} \mathrm{Ta}_{2} \mathrm{O}_{9}$ films on Pt-coated Si substrates.

strates by the MOCVD technique. The films showed superior optical, ferroelectric, and fatigue properties which meet the requirements for high-density nonvolatile memory device applications. The optimization of the deposition parameters is currently under investigation.

The authors wish to thank CERAM, Inc. of Colorado Springs, CO and IC Group of SHARP Corp. of Japan, for their support of this research.

${ }^{1}$ Ramtron Corp. (Colorado Springs, CO) started introducing its 4, 8, and 16 $\mathrm{K}$ bit FRAMs in 1988.

${ }^{2}$ G. A. C. M. Spierings, M. J. E. Ulenaers, G. L. M. Kampschoer, H. A. M. van Hal, and P. K. Larsen, J. Appl. Phys. 70, 2290 (1991).

${ }^{3}$ I. K. Yoo and S. B. Desu, Mater. Res. Soc. Symp. Proc. 310, 165 (1993).

${ }^{4}$ C. A. Paz de Araujo, J. D. Cuchiaro, L. D. McMillan, M. C. Scott, and J. F. Scott, Nature 374, 627 (1995).

${ }^{5}$ J. F. Chang and S. B. Desu, J. Mater. Res. 9, 955 (1994).

${ }^{6}$ D. S. Yoon, C. J. Kim, J. S. Lee, W. J. Lee, and K. No, J. Mater. Res. 9, 420 (1994).

${ }^{7}$ J. Si and S. B. Desu, J. Mater. Res. 8, 2644 (1993).

${ }^{8}$ L. A. Bursill, I. M. Reaney, D. P. Vijay, and S. B. Desu, J. Appl. Phys. 75, 1521 (1994).

${ }^{9}$ P. C. Fazan, Integr. Ferroelect. 4, 247 (1994).

${ }^{10}$ W. Kinney, Integr. Ferroelect. 4, 131 (1994).

${ }^{11}$ C. A. Paz de Araujo, J. D. Cuchiaro, M. C. Scott, and L. D. McMillan, International Patent No. WO 93/12542 (24 June 1993).

${ }^{12}$ K. Amanuma, T. Hase, and Y. Miyasaka, Appl. Phys. Lett. 66, 221 (1995).

${ }^{13}$ T. K. Li, T.-C. Chen, C. H. Peng, and S. B. Desu, paper presented at 7th International Symposium on Integrated Ferroelectrics held in Colorado Springs, CO, March 20-22, 1995.

${ }^{14}$ M. Klee, paper presented at 7 th International Symposium on Integrated Ferroelectrics held in Colorado Springs, CO, March 20-22, 1995.

${ }^{15}$ S. B. Desu and T. K. Li, Mater. Sci. Eng. B (to be published).

${ }^{16}$ S. B. Desu and D. P. Vijay, Mater. Sci. Eng. B (to be published).

${ }^{17}$ R. Dat, J. K. Lee, C. Basceri, O. Auciello, and A. Kingon, paper presented at 7th International Symposium on Integrated Ferroelectrics held in Colorado Springs, CO, March 22-22, 1995.

${ }^{18}$ T.-C. Chen and S. B. Desu (unpublished).

${ }^{19}$ T. K. Li, T. C. Chen, and S. B. Desu (unpublished). 